\title{
Research Paper \\ Effect of Neurofeedback Training on Improvement of Reaction Time in Elderly, Passive Males
}

\author{
Sajad Parsaei ${ }^{1}$, Nahid Shetab Bushehri ${ }^{1}$, ${ }^{*}$ Saeed Alboghebish ${ }^{1}$, Somayeh Rezaeimanesh ${ }^{1}$, Parisa Barati ${ }^{1}$
}

1. Department of Sport Psychology, Faculty of Physical Education and Sport Sciences, University of Shahid Chamran, Ahvaz, Iran.

\begin{tabular}{|c|c|}
\hline $\begin{array}{l}\text { Use your device to scan } \\
\text { and read the article online }\end{array}$ & \\
\hline 口ifition & $\begin{array}{l}\text { Citation: Parsaei S, Shetab Bushehri N, Alboghebish S, Rezaeimanesh S, Barati P. [Effect of Neurofeedback Training on Im- } \\
\text { provement of Reaction Time in Elderly, Passive Males (Persian)]. Iranian Journal of Ageing. 2016; 11(4):550-557. http://dx.doi. } \\
\text { org/10.21859/sija-1104550 }\end{array}$ \\
\hline 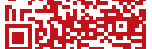 & doi : http://dx.doi.org/10.21859/sija-1104550 \\
\hline
\end{tabular}

Received: 01 Jul. 2016

Accepted: 21 Oct. 2016

Keywords:

Neurofeedback,

Brain wave, Reac-

tion time, Elderly

\section{A B STRACT}

Objectives Given the reduction of the ability to correctly predict stimuli, the aging process is often associated with an increase in reaction time. This is particularly more pronounced in the elderly. The neurofeedback program can influence the cognitive function and physical performance by auto-tuning the brain wave abnormalities. The main objective of the current study was to investigate the impact of neurofeedback exercises upon the improvement of the reaction time in elderly, passive males.

Methods \& Materials The study was a quasi-experimental research in which 18 elderly males, with an average (SD) age of 65.38 (3.12) years, were selected and randomly assigned in experimental and control groups. A YB-1000 reaction timer was used to evaluate the reaction time of the subjects across 3 sets of measurements (pretests, midtests, and posttests). The subjects in the experimental group participated in 12 neurofeedback exercise sessions (increase of beta and decrease of theta powers). To eliminate the impact of empathy, the control group was subject to a similar training plan in which they only observed the recorded waves of the experimental group exercises.

Results Statistical analysis of the results based on the MANCOVA test demonstrated a significant improvement in the reaction time of the experimental group compared with the control group following the neurofeedback exercising $(P<0.5)$.

Conclusion Based on the reinforcement or inhibition of the brain waves as well as the improvement of the memory use, neurofeedback exercises can serve as an effective means to improve the cognitive processes (e.g. the reaction time) of the elderly. 


\title{
تأثير تمرينهاى نوروفيدبك بر بهبود زمان واكنش مردان سالمند غيرفعال
}

\author{
سجاد هارسايى'، ناهيد شتاب بوشهرى'؛ "سعيد البوغبيش'، سميه رضايیمنش '، يريسا براتى'
}

ا - كروه روانشناسى ورزشى، لانشكده تربيت بدنى و علوم ورزشى، دانشكاه شهيدجمران اهوازء، اهوازء ايران.

\begin{abstract}
حكינ
تاريخ دريافت: التير هوبا

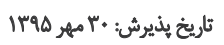

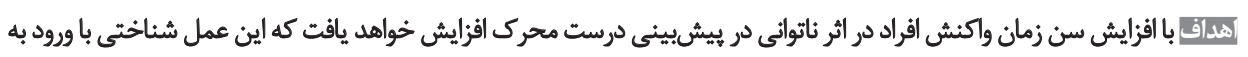

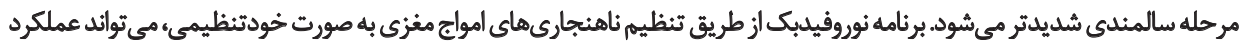

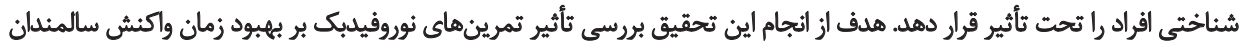

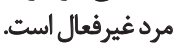

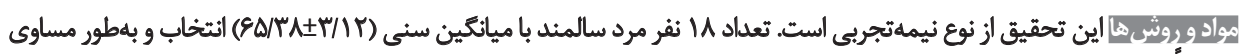

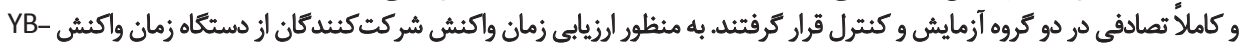

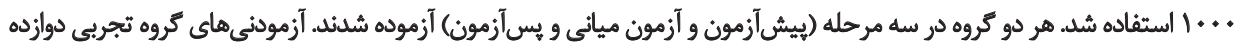

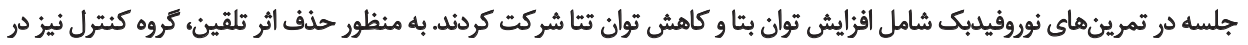

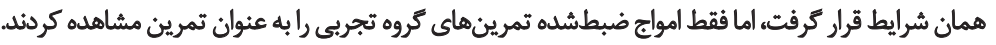

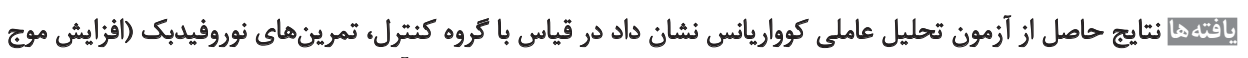

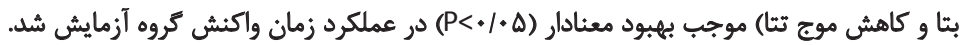

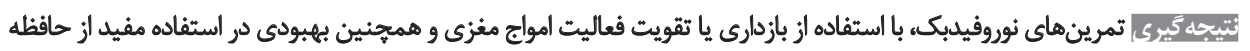

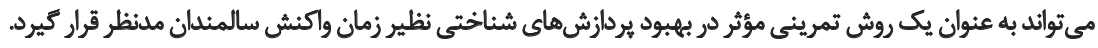

كليدوازوهها:

توروفيدبك، امواج

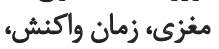
سالمئل
وجود نيامده وغيرقابل اجتناب و بركشتنايذير است. با افزايش سن

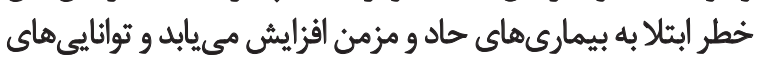

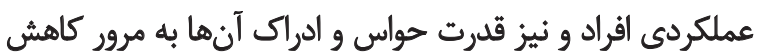

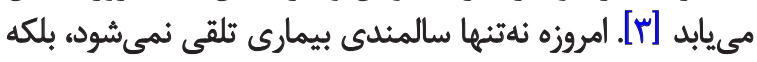

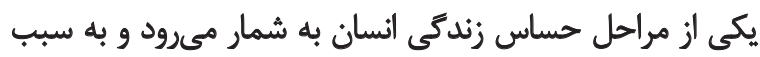

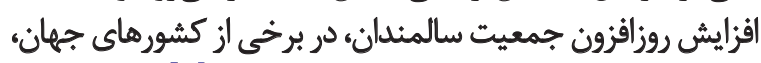

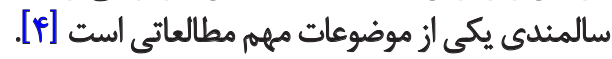
با افزايش سن در مغز نيز تغييراتى به وجود مي آيد كه باعث

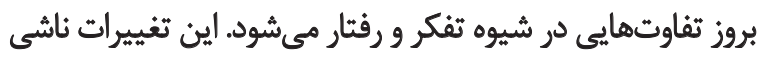

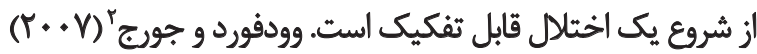

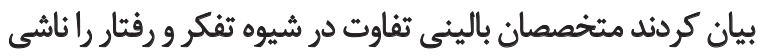

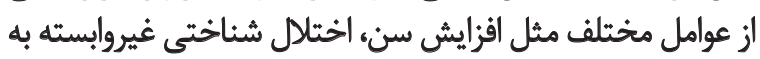

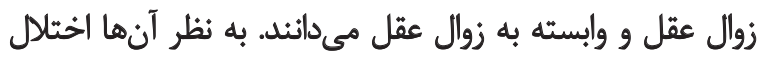
شناختى حد فاصل افزايش سن و زوال عقل است [هـ]

2. Woodford \& George
مقدمه

سالمندان افرادى هستند كه در دنياى معاصر با بيشرفتهاى

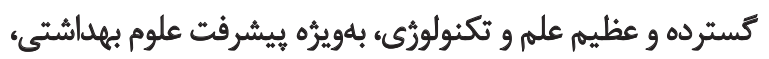

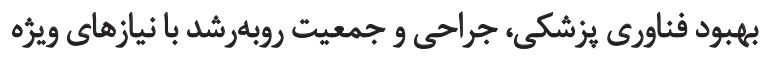

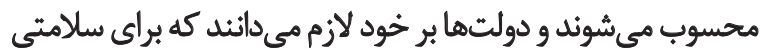

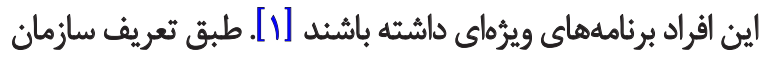

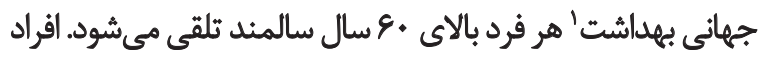

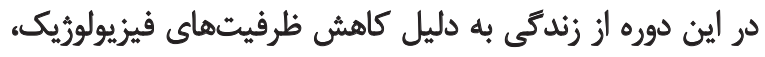

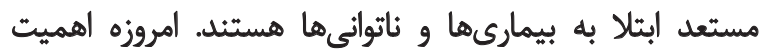

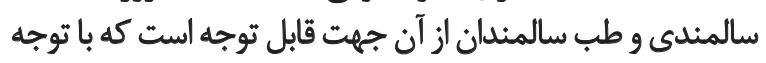

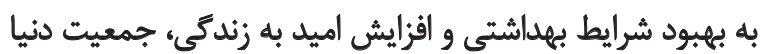

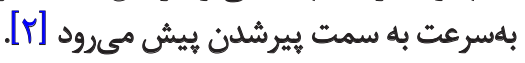

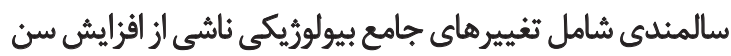

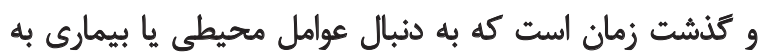

1. World Health Organization

\section{모.}

\section{*ويسنده مسئول:}

سعيد البوغييش

نشانى: اهواز، دانشكاه شهيدجمران اهواز، الشكده تربيت بلنيى و علوم ورزشى، كروه روانشناسى ورزشى.

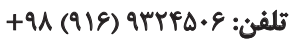
albogbish@gmail.com : يست الكترونيكى 
مركزى و سلولهاى مغزى، كاهش جريان خون به مغز، كاهش كيرندهاى اطلاعات حسى و كاهش

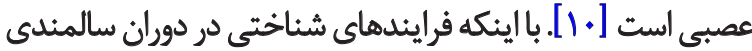

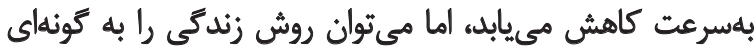

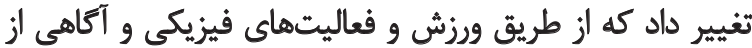

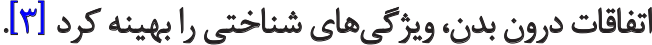

برنامه بيوفيدبك و نوروفيدبك ازجمله روشهايى است كه

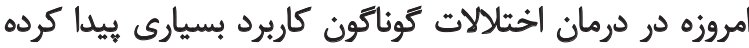

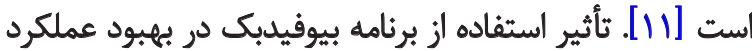

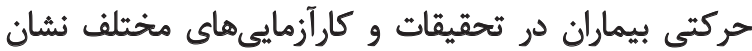

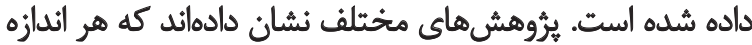

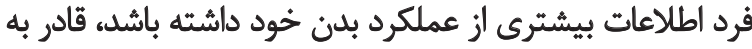

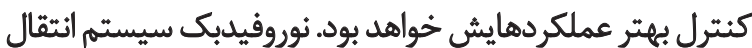

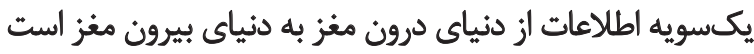

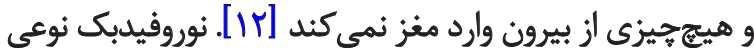

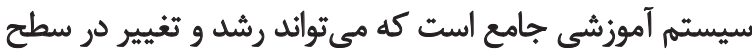

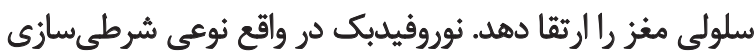

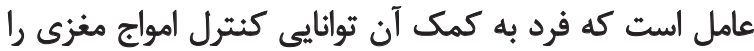

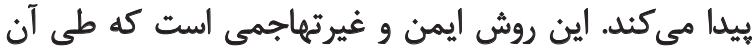

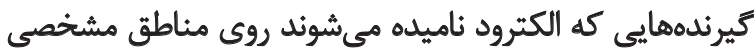

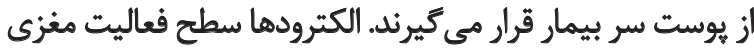

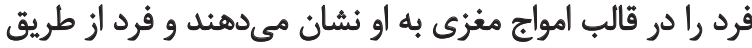

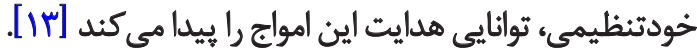

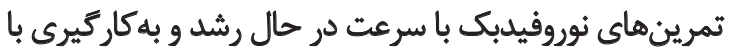

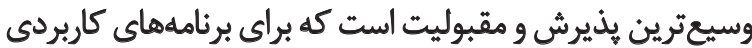

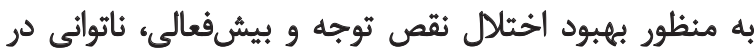

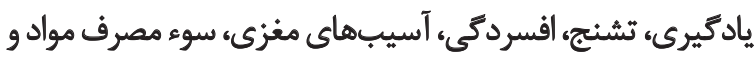

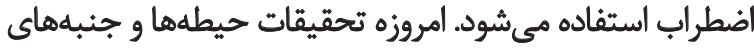

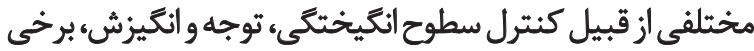

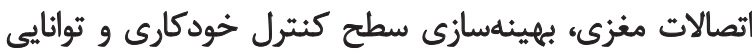

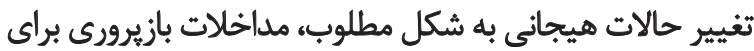

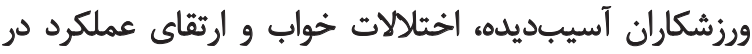

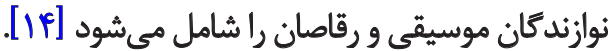

در بررسى هاى كوناكون ثأثير تمرينهاى نوروفيدبك و ارتباط

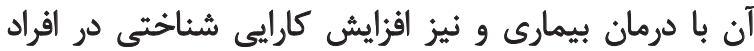

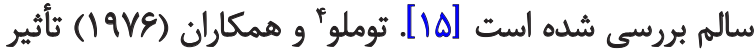

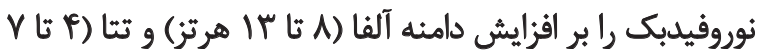

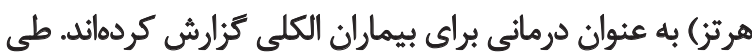

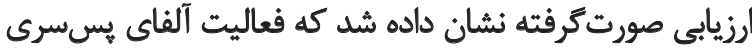

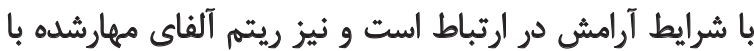

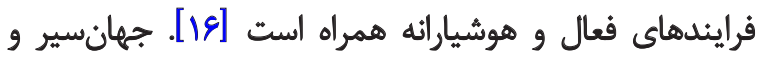

در دوره سالمندى علاوه بر تغييرات جسمانى و حركتى،

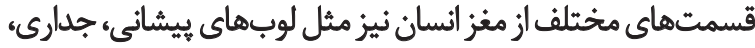

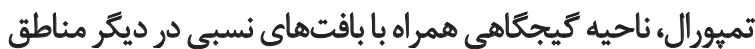

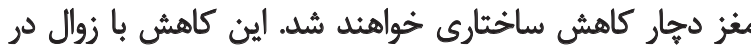

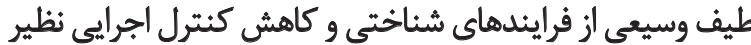

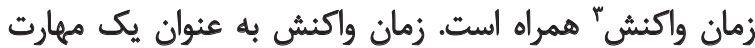

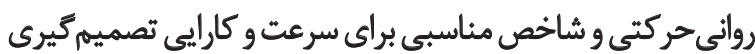

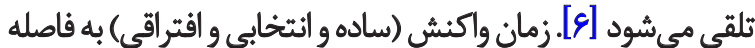

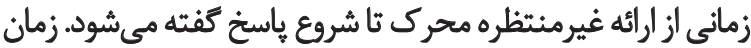

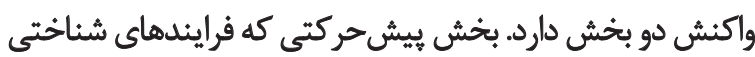

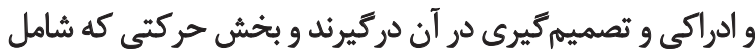

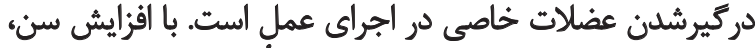

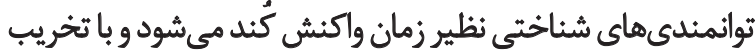

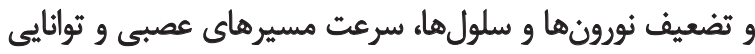

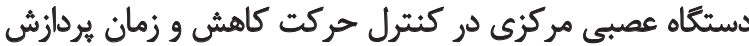

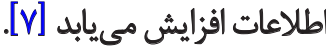

زمان واكنش براى سلامت و عملكرد انسان يك امر حياتى

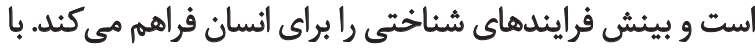

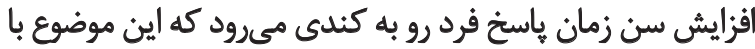

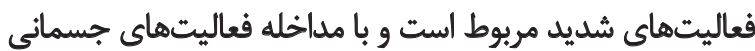

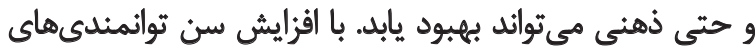

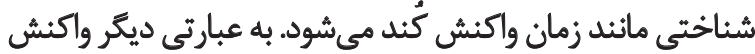

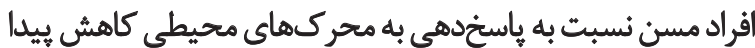

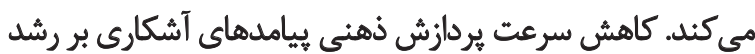

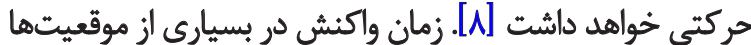

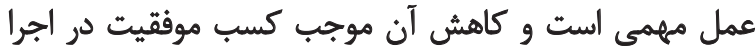

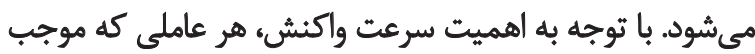

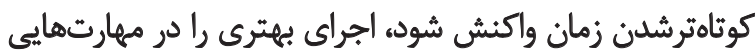

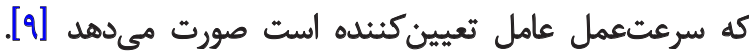

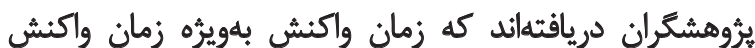

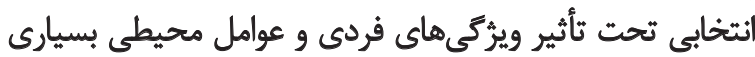

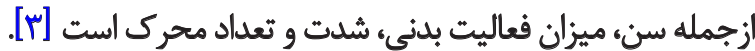

با افزايش سن و رسيلن به دوران بيرى تغييرات زيادى

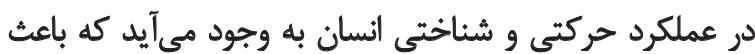

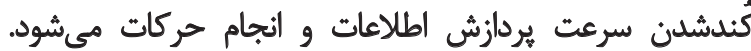

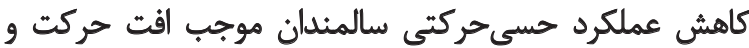

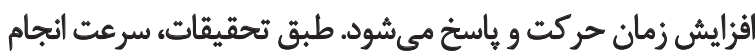

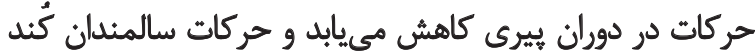

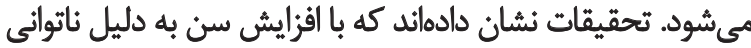

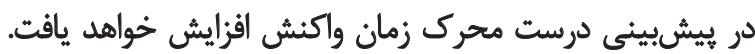

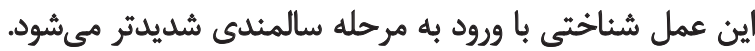

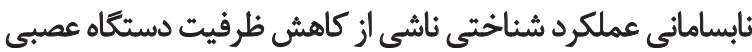

3. Reaction time 
شامل ابتلا به اختلالات نورولوزيك، بيمارىهاي مزمن نإيايدار،

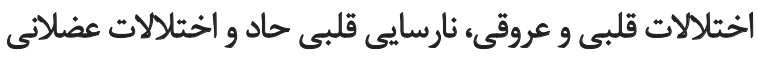

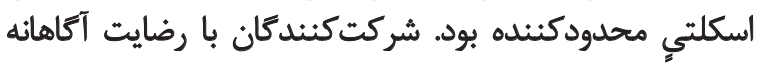

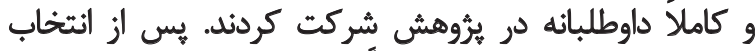

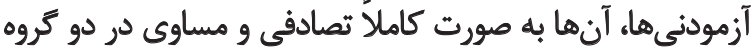

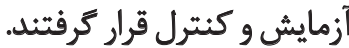

$$
\text { ابزار اندازهكيرى }
$$

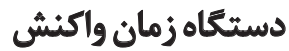

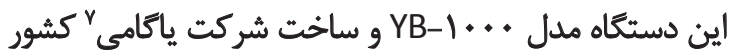

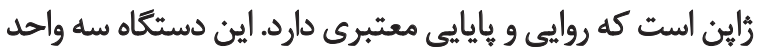

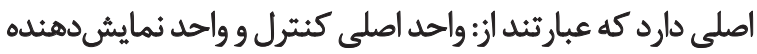

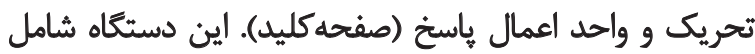

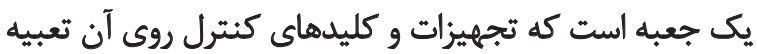

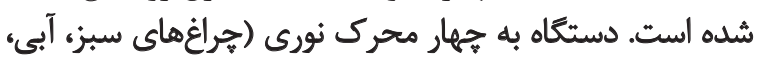

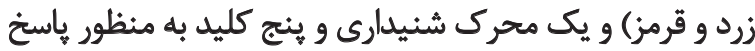

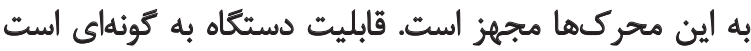

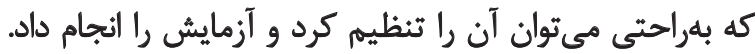

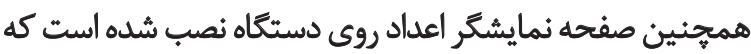

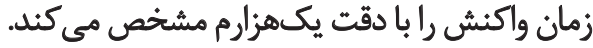

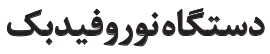

براى انجام تمرينهاي نوروفيدبك از دستكاه نوروفيدبك شامل نوريك

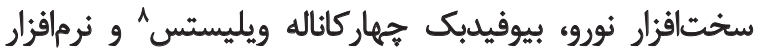

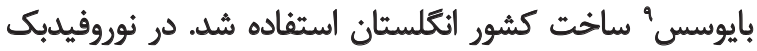

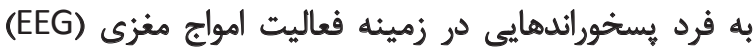

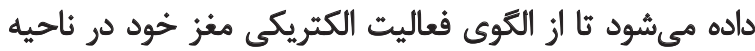

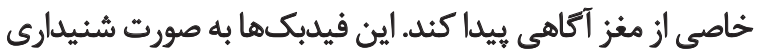

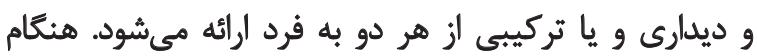

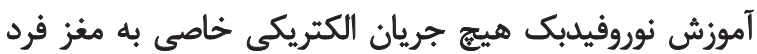

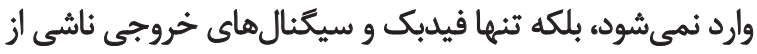

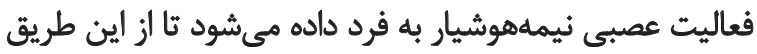

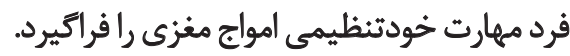

امواج مغزى با استفاده از مونتار الكترود دوقطبى و بر اساس

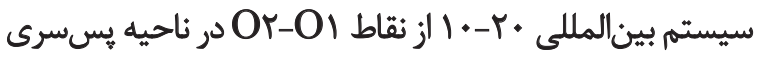

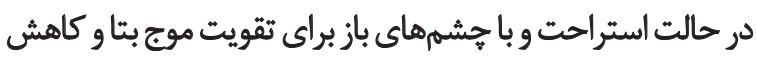

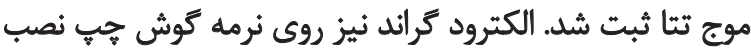

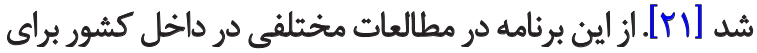

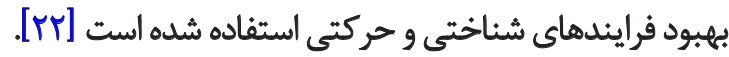

7. Yagami

8. Vilistus

9. Biosses

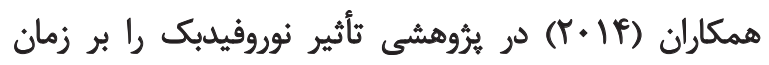

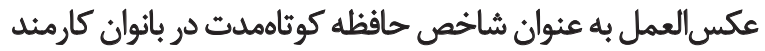

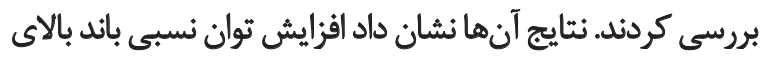

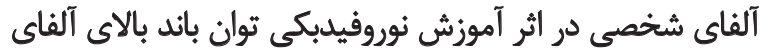

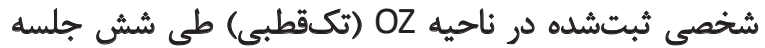

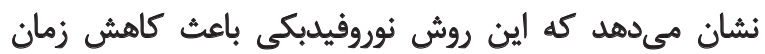

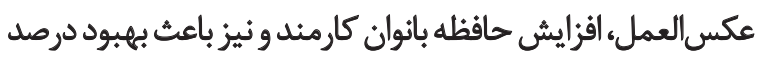
تفكيك رنك تصاوير شده است [IV]

هنسل ماير هو همكاران (ه • • (T) در تحقيقى نشان دادند تمرينهاي

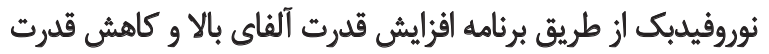

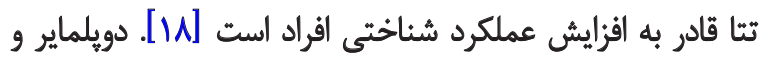

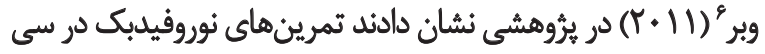

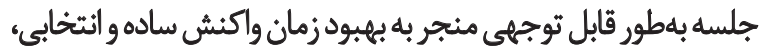

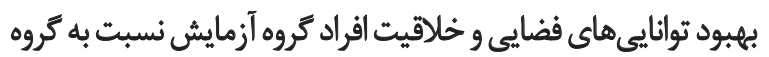

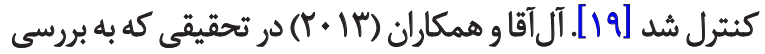

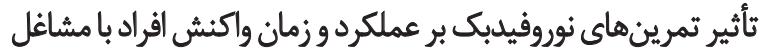

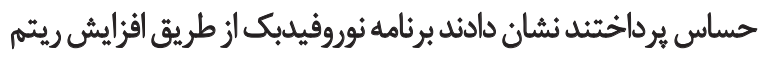

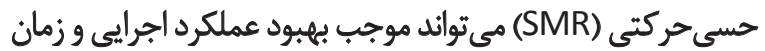
واكنش شركت كنئد آن شود [r. با توجه به اثرات مفيد و كوناكون نوروفيدبك بر جنبهاتهاى

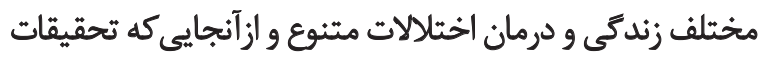

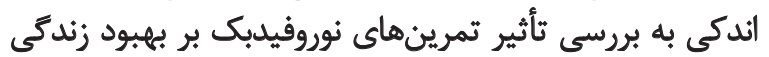

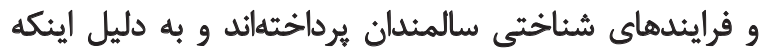

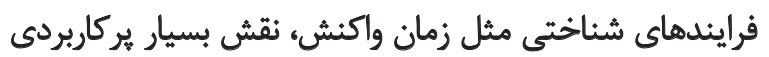

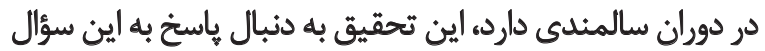

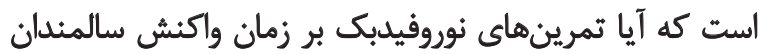
تأثير دارد ياخير آنا تمرين

\section{روش مطالعه}

مطالعه حاضر از نوع نيمهتجربي و از لحاظ هدف كاربردي

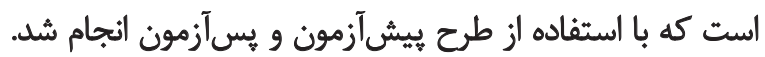

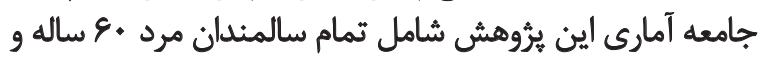

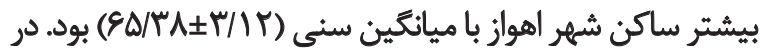

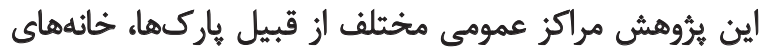

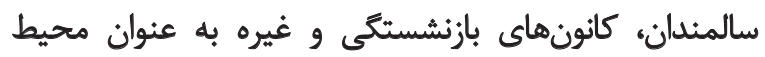

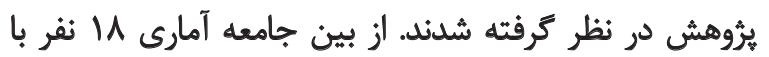

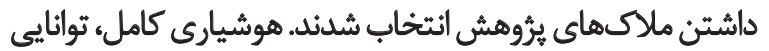

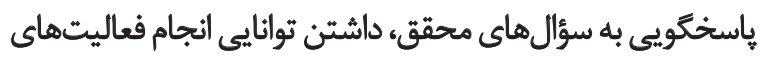

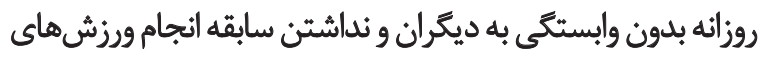

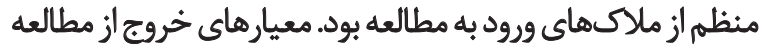

5. Hanslmayr

6. Doppelmayr \& Weber 
در اين تحقيق تمرينهاي نوروفيدبك به عنوان متغير مستقل و يافتهها

جدول شماره 1 نشان داد شاخصهاى جمعيتشناختى

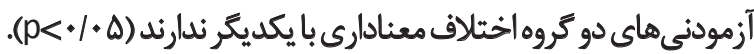

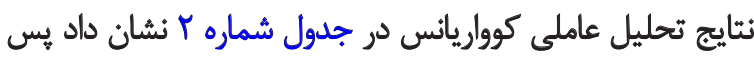

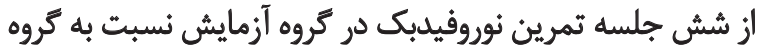

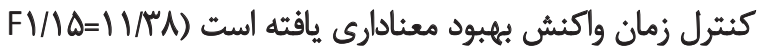

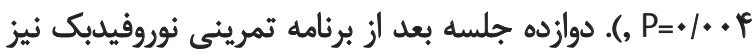

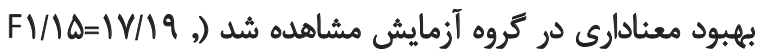

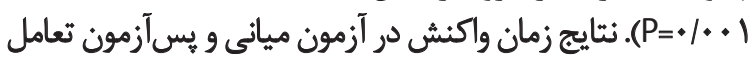

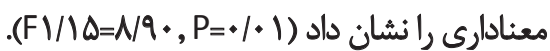

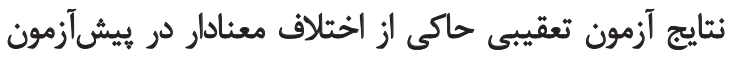

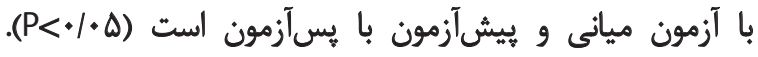

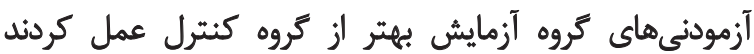

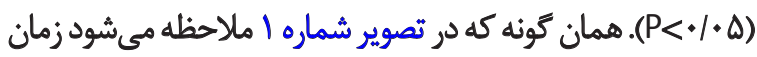

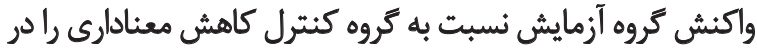

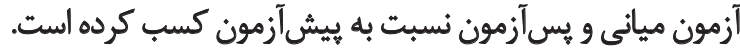

بحث

هدف ثروهش حاضر بررسى تأثير تمرينهاى نوروفيدبك بر بران

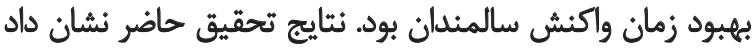

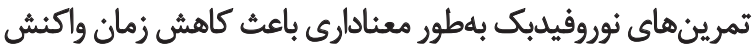

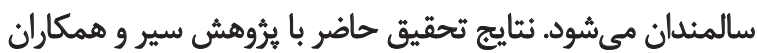
(Y. If)

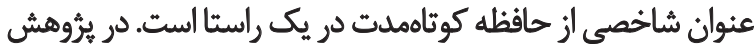

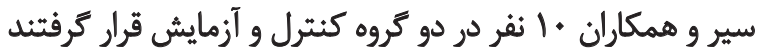

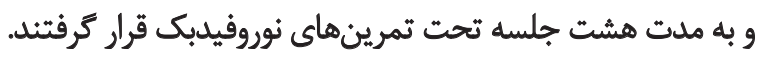

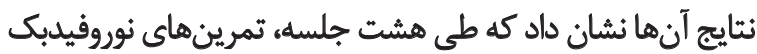

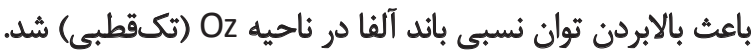

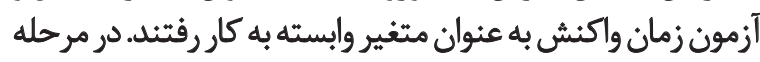

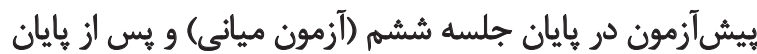

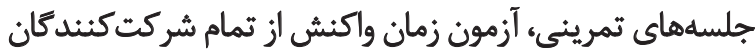

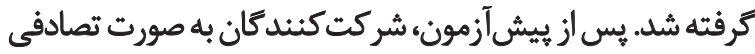

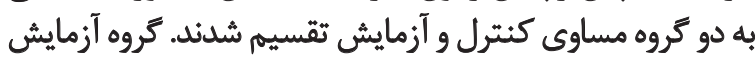

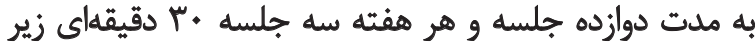

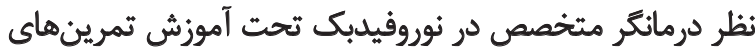

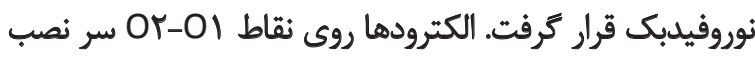

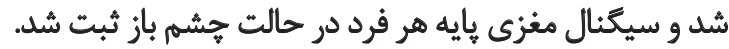
آزمودنى با مشاهده بيشروى بازىها و نمودار ستونى متحركى

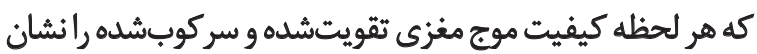

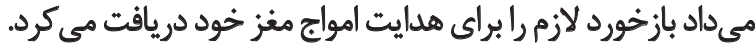

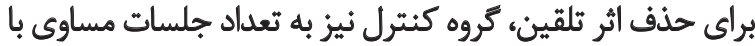

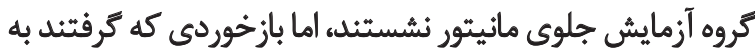

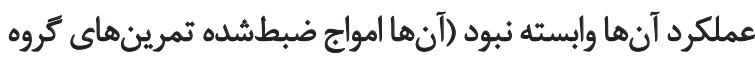

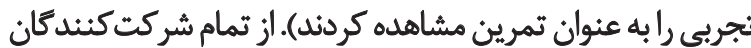

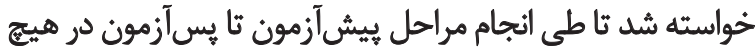

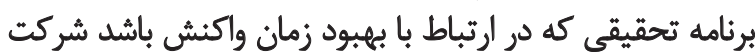

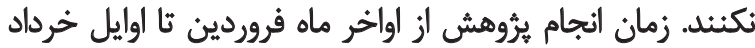

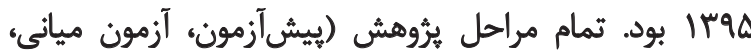

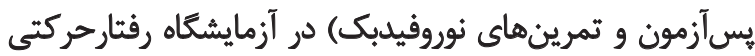

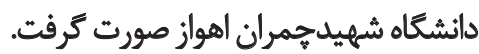

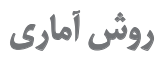

براى تجزيهوتحليل آمارى از ميانكين و انحرافمعيار به عنوان

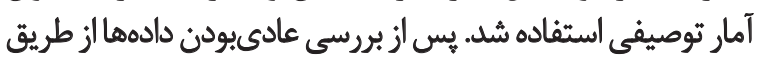

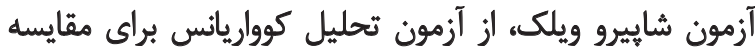

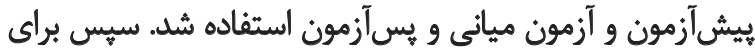

جدول ا. ميائكين و ائحراف|ستائدارد ويرّكى هاي فردى شركت كنيندكان.

\begin{tabular}{|c|c|c|c|}
\hline انحراف|ستاندارد & مياتكين & كروه & مثنير \\
\hline$r / s \varepsilon$ & $\varepsilon \Delta / \pi \varphi$ & آزمايش & \multirow{2}{*}{ سن } \\
\hline$r / 9 \Delta$ & $\varepsilon_{\Delta / / r}$ & كنترل & \\
\hline$\Delta / 1 \Delta$ & ENII & آزمايش & \multirow{2}{*}{ وزن } \\
\hline F/AV & $99 / .4$ & كتترل & \\
\hline$\Delta / 11$ & $19 \% / 09$ & أزمايش & \multirow{2}{*}{ قد } \\
\hline$V / M$ & $19 T / f$. & كتثرل & \\
\hline
\end{tabular}

$\therefore$ 
جدول r. نتايج تحليل عاملى كوواريانس زمان واكنش دو كروه آزمايش و كنترل.

\begin{tabular}{|c|c|c|c|c|}
\hline sig. & $\mathbf{F}$ & $M D \pm S D$ & كروه & أزمون \\
\hline$\%$ & $11 / \% \wedge$ & 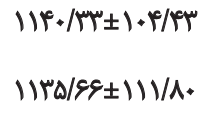 & كتزل & ييش آزمون \\
\hline $.1 .+1$ & $18 / 19$ & 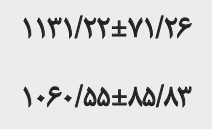 & كتمارل & آزمون ميانى \\
\hline$+1+1$ & Na. & $\begin{array}{l}11 . \checkmark \& 9 \pm W q 9 \\
99 \& / W \pm \& 91.8\end{array}$ & كنترل & يس آزمون \\
\hline
\end{tabular}

\section{L}

و وياسخدهى فرد به محيط به خاطر ابهام در سيكنالها براي

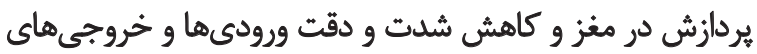

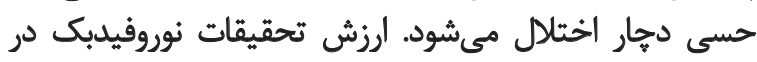

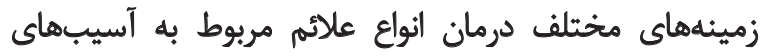
مغزى و روانشناسى ورزشى شامل توانمندسازي، افزئن إيش تمركز

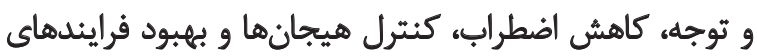
شناختى اثبات شده است اضطراب كنترل [111]

با توجه به توان تطبيقيذيرى سيستم نوروفيدبك باويزئى إنهاى

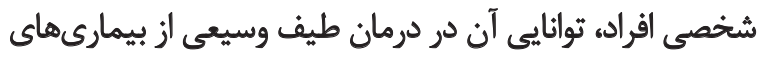

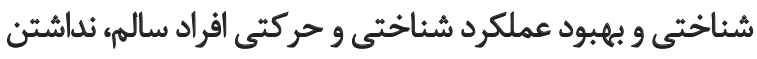

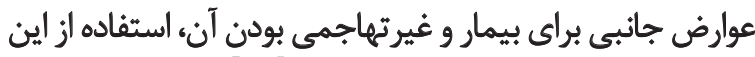

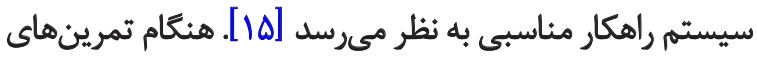

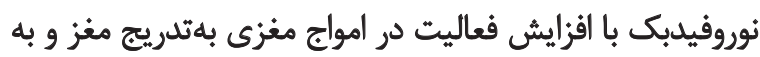

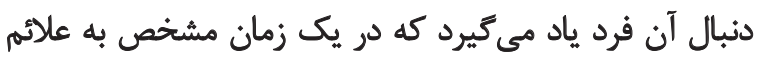

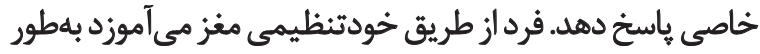

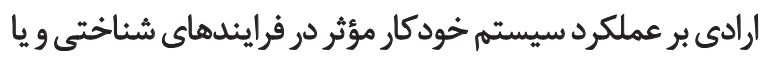

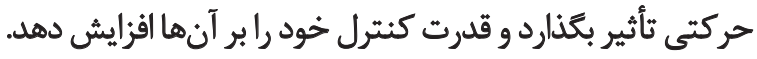

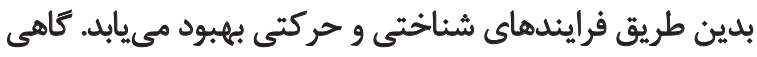

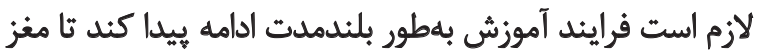

بهبود توان نسبى باند بالاى آلفا باعث كاهش زمان واكنش و افزايش

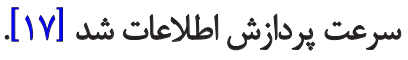

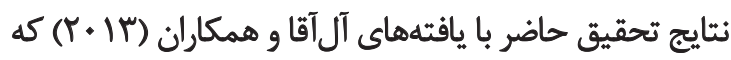

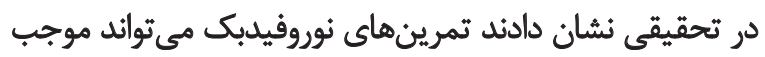

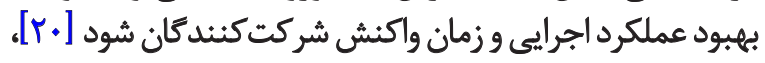

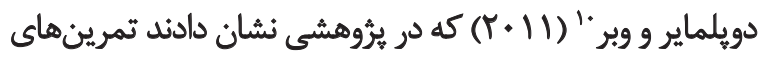

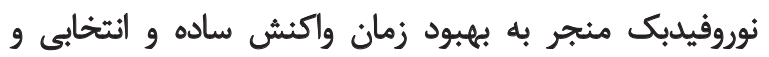

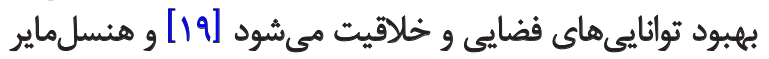

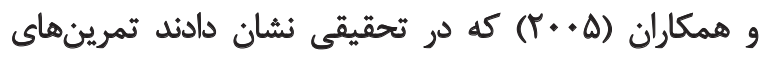

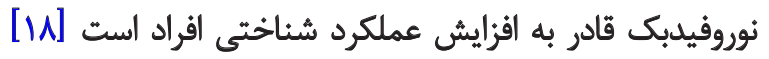

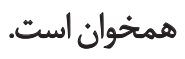

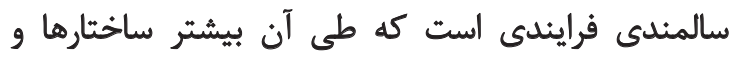

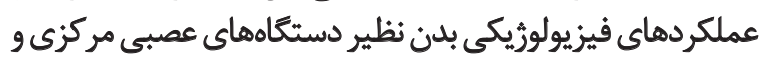

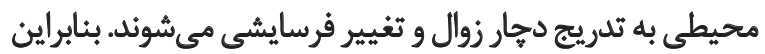

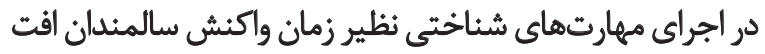

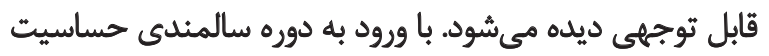

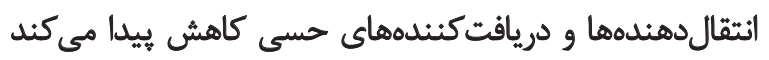
10. Doppelmayr \& Weber

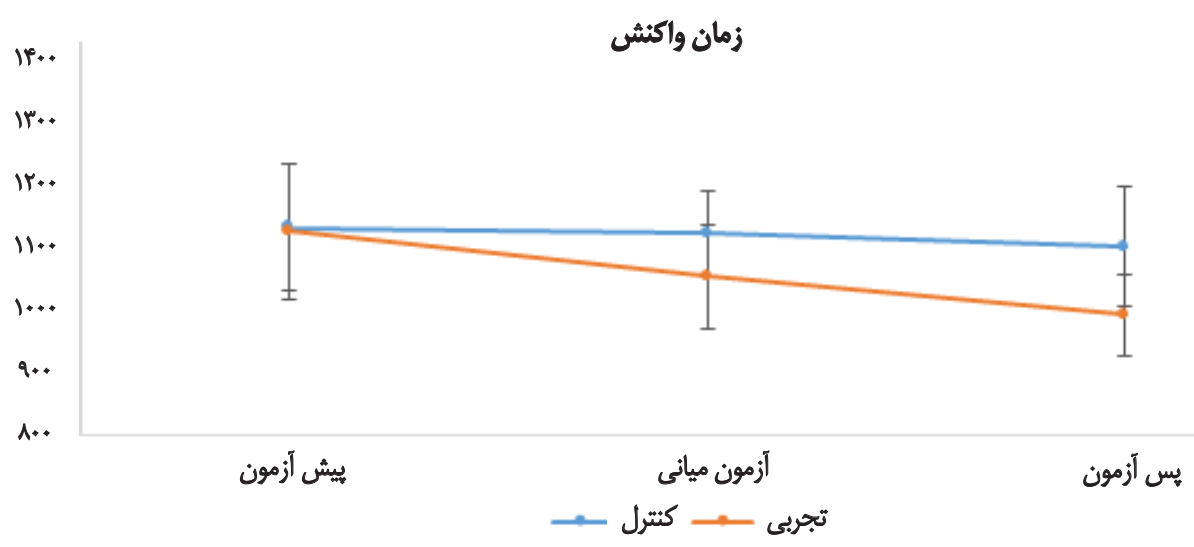




\section{References}

[1] Khezri A, Arabameri E, Hemayattalab R, Ebrahimi R. The effects of exercise and physical activity on reaction time and the elderly (Persian)]. Iranian Journal of Aging. 2014; 9(1):107-113.

[2] Ward SA, Parikh S, Workman B. Health perspectives: International epidemiology of ageing. Best Practice \& Research Clinical Anesthesiology. 2011; 25(3):305-17. doi: 10.1016/j.bpa.2011.05.002

[3] Payne V, Esax L. Human motor development [Khalaji H, Khajavi D, Persian trans]. Arak: Arak University Publication; 2005.

[4] Segal, NA, Hein J, Basford, JR. The effects of Pilates training on flexibility and body composition: An observational study. Archives of Physical Medicine and Rehabilitation. 2004; 85(12):19771981. doi: 10.1016/j.apmr.2004.01.036

[5] Woodford HJ, George J. Cognitive assessment in the elderly: A review of clinical methods. QJM. 2007;100(8):469-84. doi: 10.1093/ qjimed/hcm051

[6] Rahmani M, Heirani A, Yazdanbaksh K. [The effect of Pilates training on improving the reaction time and balance of sedentary elderly men (Persian)]. Journal of Modern Rehabilitation. 2015, 9(3):44-53.

[7] Tamm L, Narad ME, Antonini TN, O'Brien KM, Hawk LW Jr, Epstein JN. Reaction time variability in ADHD: A review. Aerotherapeutics. 2012; 9(3):500-508. doi: 10.1007/s13311-012-0138-5

[8] Krezman H, Chetrit A, Brin L, \& Toren O. Characteristics of falls in hospitalized patients. Journal of Advanced Nursing. 2004; 47(2):223-9. doi: 10.1111/j.1365-2648.2004.03080.x

[9] Wang J. Reaction-time training for elite athletes: a winning formula for champions. International Journal of Coaching Science. 2009; 3(2):258-269.

[10] Pierson WR, Montoye HJ. Movement time, reaction time, and age. Journal of Gerontology 1985; 13(4):418-421. PMID: 13611237

[11] Woodford H, Price C. EMG biofeedback for the recovery of motor function after stroke. Cochrane Database of Systematic Reviews. 2007; (2):45-85. doi: 10.1002/14651858.cd004585.pub2

[12] Eskandarnejad M, Abdoli B, NAzari MA, Vaez Mousavi SMK [The effects of neurofeedback on the performance of beginner archery (Persian)]. Journal of Motor Behavior. 2010; 2(5):57-73.

[13] Wing K. Effect of neurofeedback on motor recovery of a patient with brain injury: A case study and its implications for stroke rehabilitation. Topics in Stroke Rehabilitation. 2001; 8(3):45-53. doi: 10.1310/4g2f-5plv-rnm9-bggn

[14] Yucha C, Gilbert CH. Evidence-based practice in biofeedback and neurofeedback. Wheat Ridge, Colorado: Association for Applied Psychophysiology and Biofeedback; 2008.

[15] Kahrizi N. [The effect of yoga's training on improving the reaction time, balance static and dynamic of sedentary elderly men in Kermanshah (Persian)] [MSc. thesis]. Kermanshah: University of Kermanshah; 2013.

[16] Twemlow SW, Bowen WT. Sociocultural predictors of selfactualization in EEG biofeedback induced self-actualization in alcoholics. Journal of Biofeedback. 1977; 40(2):591-8. doi: 10.2466/ pr0.1977.40.2.591

$$
\text { بتواند به مرور قابليتهاي قبلى خود را بازيابد [rr] }
$$

افزايش سن موجب انحطاط و زوال سلولهاي عصبى در نواحى

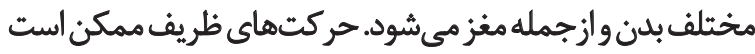

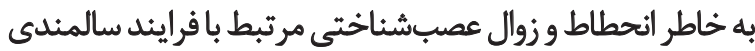

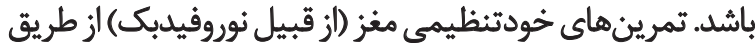

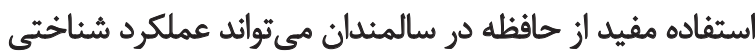

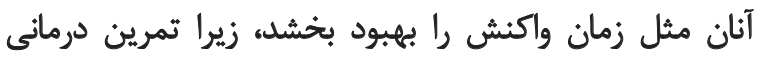

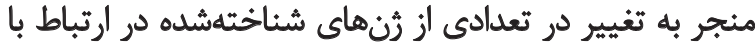

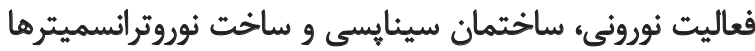

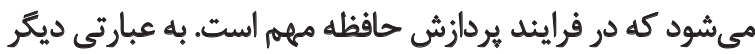

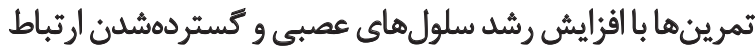

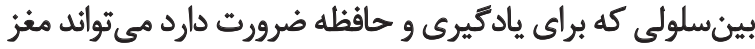

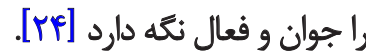

به منظور تشخيص حضور محرك از زمان واكنش استفاده

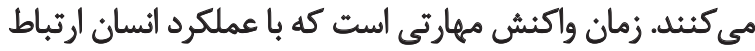

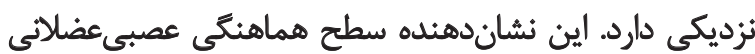

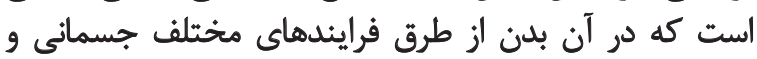

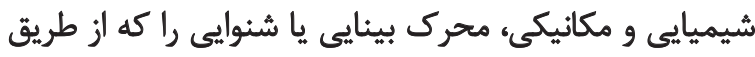

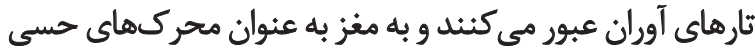

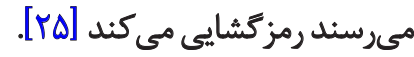

هنكام انجام تمرينهاى نوروفيدبك بر اساس اصول علم

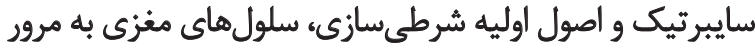

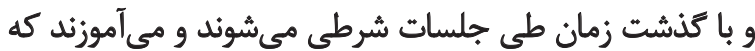

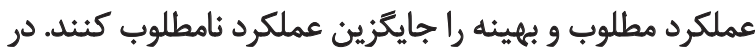

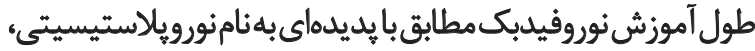

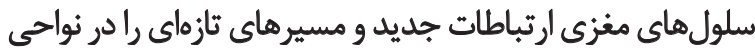

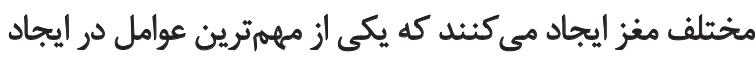

$$
\begin{aligned}
& \text { حافظه و يادكيرى و تمركز است. } \\
& \text { نتيجدئيرى نهايي }
\end{aligned}
$$

تمرينهاى نوروفيدبك با استفاده از بازدارى يا تقويت فعاليت

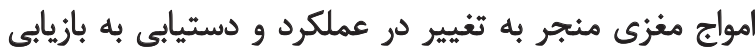

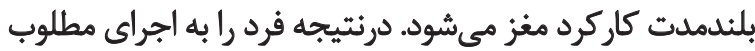

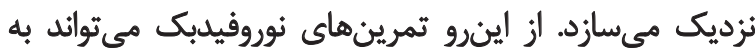

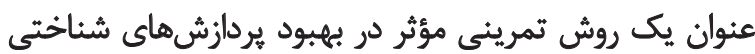
نظير زمان واكنش سالمندان مدنظر قرار كيرد.

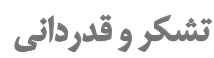

از تمامى شركت كنندكان در اين برؤوهش كه صبورانه در مر مراحل

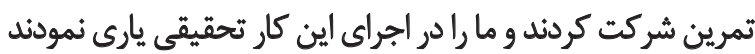

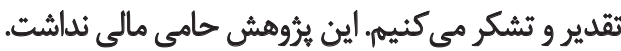


[17] Jahanseir M, Firooz Abadi SM, Ghoshouni M, Motie Nasrabadi A. [The effect of individual upper alpha band enhancing neurofeedback on reaction-time as an indicator of short-term memory in women employees (Persian)]. Iranian South Medical Journal. 2014; 17(5):834-846.

[18] Hanslmayr S, Sauseng P, Doppelmayr M, Schabus M, Klimesch $\mathrm{W}$. Increasing individual upper alpha power by neurofeedback improves cognitive performance in human subjects. Applied Psychophysiology and Biofeedback. 2005; 30(1):1-10. doi: 10.1007/ s10484-005-2169-8

[19] Doppelmayr M, Weber E. Effects of SMR and theta/ beta neurofeedback on reaction times, spatial abilities, and creativity. Journal of Neurotherapy. 2011; 15(2):115-29. doi: 10.1080/10874208.2011.570689

[20] Nabavi Aleagha F, Naderi F, Heidarei A, Nazari M, Nicksirat A, Avakh F. [The effectof neurofeedback (SMR training) on performance and reaction time of individuals who undertake difficult tasks (Persian)]. Ebnesina. 2014; 15(4):36-41.

[21] Hammond DC. Neurofeedback for the enhancement of athletic performance and physical balance. The Journal of the American Board of Sport Psychology. 2007; 1(1):1-9.

[22] Azarpaikan A, Torbati HT, Sohrabi M. Neurofeedback and physical balance in Parkinson's patients. Gait \& posture. 2014; 40(1):177-81. doi: 10.1016/j.gaitpost.2014.03.179

[23] Sadeghi-Naeinipour N, Nazari MA, Alizade-Zarei M. Kamali M. [The effect of neurofeedback training on balance performance and attention shifting in children with reading disorder (Persian)]. Journal of Research in Rehabilitation Sciences. 2013; 7(3): 32-39.

[24] Klimesch W. EEG alpha and theta oscillations reflect cognitive and memory performance: A review and analysis. Brain research reviews. 1999; 29(2-3):169-95. doi: 10.1016/s0165-0173(98)00056-3

[25] Shelton J, Kumar GP. Comparison between auditory and visual simple reaction times. Neuroscience and Medicine. 2010; 1(1):3042. doi: $10.4236 / \mathrm{nm} .2010 .11004$ 